\title{
On Reform of College English Teaching Based on the FiF Smart Learning Platform*
}

\author{
Xiaoping Tan \\ School of Foreign Languages, Leshan Normal University, Leshan, Sichuan, 614000, China
}

\begin{abstract}
The world's educational reforms evolve dramatically along with the rapid development of science and technology, and promoting education informatization has become the national strategy of many countries. To implement the Action Plan for Education Informatization 2.0 issued by the Ministry of Education of the People's Republic of China and further integrate the information technology into classroom teaching to achieve innovations in teaching, Leshan Normal University has introduced the FiF (For Ideal Future) Smart Learning Platform, developed by iFLYTEK Co.,Ltd.. Giving a full play to the platform's functions, teachers are actively practicing the graded and classified College English teaching reform, as well as flipped classroom model and blending teaching model, thereby having improved the efficiency in teaching. The teaching empirical research has suggested that the FiF Smart Teaching Platform plays a positive role in improving students' oral English and comprehensive English ability.
\end{abstract}

Index Terms - the FiF smart learning platform, College English teaching reform, graded and classified teaching, flipped classroom teaching, blending teaching

\section{INTRODUCTION}

With the rapid development of technologies such as artificial intelligence, big data, block chain, great changes have taken place in the demand for talents and the form of education. All countries in the world are striving to promote education informatization, which refers to the comprehensive application of modern information technology based on computer multimedia and network communication in the process of education, aiming at the promotion of the overall reform of the education system and making it adapt to the new requirements of the coming information society for the development of education.(He Jianwu, 2002)In 2010 the United States Federal Ministry of Education promulgated Transforming American Education: Learning Powered Technology, National Educational Technology Plan 2010 to guide the future development of national education informatization. The plan advocated the transforming in the fields of technology-enabled learning, evaluation, teaching, infrastructure, evaluation and so on, proposing a new learning model of technological empowerment.(Zhu zhiting, Guan yuqi, 2014)In 2005 the British government formulated a plan for Taking Advantage of Information Technology to Promote Teaching Methods and Child Services (Ma Ning, Zhou Pengqin, xie Minyi, 2016) and in 2008 the government introduced Taking Advantage of Technology: Next Generation Learning Strategy (2008-2014) with two stage plans (2009-2012, 2010-2013). (Ma Yuanli, Fei Long) In March 2016, the United Kingdom issued the Department for Education. DfE Strategy 2015-2020: Word-class Education and Care, (Ma Ning, Zhou Pengqin, xie Minyi, 2016) which established the education development strategy and plan for the next five years. Denmark unveiled the Great Plan of Information Technology in 2010 and Germany launched Digital Education Strategy 2030 in October 2016. (Liu Jialiang, Pan Tangxian, 2017)Australia launched a seven-year Digital Education Revolution (from 2008 to 2014). (Wang Jijun, 2015)In recent years, Korea has actively explored the practice of U-learning on the basis of E-learning through the Internet, creating an educational environment for students to learn at any time, anywhere by using any terminal.(Gao Dandan, Zhang Jiping, 2008)

The Chinese government also attaches great importance to the construction of education informatization. It has promulgated the Planning Outline of National Medium and Long-term Education Reform and Development (2010-2020), (Group Office Working on The Planning Outline of National Medium and Long-term Education Reform and Development. 2010) the Ten-Year Plan for the Development of Education informatization informatization (2011-2020), (Ministry of Education of the People's Republic of China, 2012) the 13th Five-Year Plan of Education informatization, (Ministry of Education of the People's Republic of China , 2016) and as well as the 13th Five-Year Plan for the Development of National Education (the State Council of the People's Republic of China, 2017) and some other programmatic documents. In particular, the formal proposal of the Action Plan for Education Informatization 2.0 put out by the Ministry of Education of the People's Republic of China in April 2018, (Ministry of Education of the People's Republic of China,2018) marks that China's education informatization has entered the 2.0 era from the 1.0 era, calling for us to focus on the new demand for talent cultivation in the new era, strengthening the concept of ability-based talent training, taking education informatization as an endogenous variable of educational system reform to support and lead the development of education modernization, promoting the renewal of educational concept, the reform of educational models and the restructuring of educational systems, making our country's education

\footnotetext{
${ }^{*}$ This paper is one of the achievements of the project supported by China Educational Technology Association (Project No. QY105-018).
} 
informatization play a global leading role, contributing Chinese wisdom and program to the development of international education informatization. As a national strategy, education informatization is ushering in great opportunities for historical development.

\section{Practice of Reform of College English Teaching Based on the FiF SMart Learning Platform}

In order to keep pace with the change and cultivate innovative talents, Leshan Normal University has launched a new round reform of College English teaching models and methods since 2017, based on the FiF Smart Learning Platform.

\section{A. Concept Definition}

1. The FiF Smart Learning Platform and the FiF Oral Language Training System

The FiF Smart Learning Platform, integration of teaching, learning, testing and assessing, developed by the iFLYTEK (iFLYTEK CO.,LTD.), comprising many functional sub-modules including the FiF oral language training system, the FiF online course, the FiF testing system, the FiF intelligent marking for all subjects and the FiF foreign language learning resource library and so on, aims at integrating all the applications of educational ecology and creating the platform for intelligent learning. In our oral English teaching we are taking full advantage of the FiF oral language training system.

The FiF oral language training system, as an informationized oral language learning platform developed by FiFEDU.COM, based on the international leading intelligent speech technology of the iFLYTEK, covers training contents of professional and intelligent oral language assessment, adapting the multi-terminal oral language teaching and management system. In teaching feedback, teaching content, teaching results and mobile teaching, this system helps teachers to apply new information technology to effectively carry out oral English teaching activities and check students' learning progress, which breaks through the limitations of traditional oral English teaching. All in all, it can help students to practice their spoken English in different fields at any time and anywhere, get immediate intelligent evaluation feedback, improve their oral language ability effectively, and stimulate their internal learning motivation. Students and teachers can use it both through computers and mobile applications, which highlights the initiatives, mobility and ubiquitousness of modern learning patterns. What's more, the system also helps schools explore the construction of oral language course of college English under the new information technology and then establish a well-directed teaching model.

2. Graded and Classified Teaching

Graded teaching means that schools compile students according to their existing knowledge level, learning ability and learning objectives, grading them into different levels of classes, implementing different types of teaching so that students at all levels can get better development on the original basis.

Classified teaching refers to the establishment of different curriculum systems according to students' existing foundation, learning ability, interests and future career, so that students can choose the appropriate curriculum to receive education independently according to their own actual and personal development needs.

\section{B. Theoretical Basis}

As early as two thousand years ago, Confucius, a great educator in China, put forward the principle of teaching students in accordance with their aptitude. He advocated targeted education according to students' personality and specialty, paying attention to remedy the shortcomings, making the disciples develop their strengths and avoid their weaknesses, and ultimately cultivated 72 sages with their own merits. (Liu Ju, Zhang Yunyun , 2015) Under the background of modern education, teaching according to one's aptitude means that by sharing the common training goal, teachers should proceed from the students' reality, put forward different requirements according to the specific differences of characters, interests, abilities and original foundations of the teaching objects, and carry out different teaching practice purposefully so that each student can develop his strengths, avoid his weaknesses, and make progress on his own basis.

Constructivist Theory holds that learning is the process where learners actively construct the meaning of knowledge. (Zhu Cuiping, 2004) On the basis of existing knowledge and experience, learners recognize and code new information, and reconstruct their own understanding of knowledge. Specifically, in education, students should understand or absorb the knowledge explained by teachers, incorporate new knowledge into the learner's brain schema, so as to achieve knowledge recognition and understanding. If what the teacher teaches is too difficult or too simple, it will not be easy for learners to construct, nor easy to understand and master. Therefore, the teaching content must conform to the actual level of students, fully reflect their individuality, and consider the actual needs of students with different educational backgrounds. Constructivist Theory also holds that people are active learners. In the process of teaching, it emphasizes that students are the main body of learning. Teachers should attach importance to mobilizing students' own initiative, which is consistent with the "people-oriented" concept. Graded teaching is based on the theory of teaching students in accordance with their aptitude, which has been widely implemented in colleges and universities with many scholars involved in. For example, Wen Shengfang (2018) carried out the research of graded college English teaching under the guidance of the concept of "result-oriented" education; Wu Wanxiang (2013) and Liu Zhao (2011) proposed that colleges and universities should construct a dynamic graded teaching model; Lu Haibin (2009) advocated the 
exploration of graded college English audio-visual teaching reform under the multimedia teaching model; Guo Shuang (2011) attempted to explore graded College English teaching model under the network environment. Xie Qiao (2010), Yang Min and Pan Junfeng (2009) also published relevant research papers. However, throughout the reform of college English teaching, graded teaching pattern is common there while very few schools have implemented classified teaching pattern, and even fewer schools has carried out the practice of college English graded and classified teaching mode based on FiF Intelligent learning platform. So it is of great necessity to explore and study in this regard.

\section{Practice of Reform of College English Teaching Models and Methods}

In September 2017, based on the FiF oral language training system, Leshan Normal University began the practice of reform of college English teaching models and methods according to students' ability, interest and the difficulty of learning content.

1. Graded and Classified Teaching Model Reform

Due to the geographical location, profession settings, employment prospects and many other factors, students in our school are not particularly abundant, and their English level is uneven when entering the school. Especially for science majors, English proficiency varies greatly. Moreover, students have different hobbies and career plans in the future, and their needs for English learning are also different. If we teach based on common classes, the students with poor proficiency may fall behind while the good may not be satisfied. In order to better implement the principle of "teaching students according to their aptitude" and embody the teaching concepts of "people-oriented" and "student-centered", since September 2017 Leshan Normal University has been carrying out graded and classified college English teaching among the freshmen of five science colleges, namely, the College of Mathematics and Information Science, the College of Chemistry, the College of Physics and Electronic Engineering, the College of Computer Science and the College of Life Sciences.

After entering the school, students of these five colleges will be organized to take the entrance examination of college English, based on which students are divided into three graded classes numbered A, B and C. Class A contains students with good English proficiency, accounting for about $20 \%$ of the total, Class B contains students with average English proficiency, accounting for about $50 \%$ of the total, and Class C contains students with poor English proficiency, accounting for about $30 \%$ of the total. The course during the first school year is general English for the students of all levels. Since students with similar levels gather in one teaching class, teachers give lectures according to their ability so that they can understand their teachers very well. In addition, it is quite easy for the students to interact with each other and with their teachers. Classes always go smoothly, so do the interaction between the teacher and the students and the interaction among the students.

During the second year, classified teaching is implemented in the five colleges, and students with similar needs are concentrated in one teaching class. College English classes are divided into the following six types: ordinary classes (the continuation of the teaching mode in the first school year with the same level of students in principle), ready-for-exam classes oriented for CET-4 and CET-6, ready-for-postgraduate classes, ready-for-exam classes oriented for studying abroad, oral English classes and minority language classes (Japanese/French). In the second academic year, the students of the five colleges are required to choose independently the type of teaching classes according to their own interest, need of personal development and future career. In this way every student can get what they want in English class.

\section{Blended Teaching Model Reform}

Blended teaching model, which connects the advantages of online teaching and traditional teaching, is a kind of "online" plus "offline" teaching. Through the organic combination of the two teaching organizational forms, learners can make a deep understanding step by step. And teachers can give full play to the leading role, guiding, inspiring and monitoring students' learning activities; students as the main body of learning can also fully reflect their initiative, enthusiasm and creativity. (He Kekang, 2004) In oral English class, teachers use the first half of the class time to deal with the knowledge points in the textbooks, conduct demonstration exercises and comment while for the second half of the class, students use FiF oral training system to train themselves online. Teachers can give guidance, answer questions and do second demonstration exercises in class. After class, teachers arrange training tasks online. After completing the training task, students can get an immediate assessment report, evaluate and reflect on their learning process. Teachers can check the performance report of the task, understand the various learning data and the distribution of the results, and take this into the usual results. Well, the following is an example.

When talking about characters, the teacher will guide the students to have a simple MIND-MAP in class to conceive their own content, such as Who the singer is; How the singer became famous; What is special about his/her music and explain whether you like the singer or not. Then the teacher gives a short passage about Jay Chou on the FiF oral language training system for students to do follow-up exercises. In the next class, the teacher guides the students to learn some key words and expressions. For example, a singer-songwriter and an instant hit, namely the most popular work upon being released. Students are provided with some other related expressions, such as "signing contracts", "music critics", "music industry", "being famous overnight" and so on for vocabulary expanding. Then, let the students talk about a celebrity. Students are supposed to be very enthusiastic on this topic and can not wait to talk about their idols with active atmosphere. However, due to the limited class time, it is impossible for every student to give a presentation. Therefore, the teacher arranges for each student to input his task introduction into the FiF oral language 
training system after class. Having completed the training task, students can get an immediate assessment report, and evaluate and reflect on their learning process. Besides the teacher, other students can check the results report and grade each other. Through this kind of teaching model, the development of multi-channel, multi-form teacher-student, student-student and human-machine interaction will help to establish a complete and harmonious language ecology, and finally promote students' language ability.

3. Flipped Class Model Reform

Flipped class model means that students learn knowledge at home, and the classroom serves as a place for interaction between teachers and students or among students, including answering questions, solving puzzles, applying knowledge and so on, so as to achieve better educational effect. (Zhong Bingliu, Song Shuqiang, Jiao Lizheng, 2013) It emphasizes the main position of students' learning, requires students to focus on project-based learning and cooperation to complete tasks. Under this model, the information that teachers need to teach in traditional classroom can be obtained by students' initiative learning and cooperation with group members before class, which helps teachers have more time to communicate with students in class. Before oral English class, teachers set oral training tasks related to the content of the textbook on the FiF oral language training system, which involves articles about people's preferences, personal arrangements, such as "an influential person" and "an ideal job". Teachers will arrange topic-related articles and require students to learn online independently by applying the FiF oral language training system, so that students can familiarize themselves with topics, expand their thinking, and obtain more language resources. Teachers can get students' learning results systematically and prepare lessons based on them. In oral English class, students carry out oral communication through pair and group work based on what they have learned actively before class, while teachers just instruct key knowledge and answer questions in an interactive way. After class, teachers assign extended tasks on the platform . This kind of teaching model subverts the traditional teaching process pattern and structure, leading to the change of the roles of teachers and students, by which students can achieve individualized and initiative learning according to their own learning style and teachers can meet students' needs through classroom teaching and cooperation. (Luan Tao, 2016) When teaching Unit 3 of Volume 2 of the New Horizon College English Viewing, Listening \& Speaking (Version 3), Time Out, the author applied flipped class model through the FiF oral training system. The teaching approaches are as follows.

a. Before-class Stage

Firstly, the teacher searches the resources bank of FiF oral language training system for some exercises related to the content of this unit, such as Cycling (elementary), Bar Fun Time (elementary), and the Imitation part of Unit 3 Time Out. Then the teacher assigns these exercises for students to study by themselves. At the same time, aiming at the important and difficult points of students' self-study, the teacher should integrate the teaching materials reasonably and to design effectively the teaching content and interaction of this unit.

Students $\log$ on to the FiF oral language training system before class to check the assignments delivered by the teacher, complete their self-study, understand the daily communication and expressions of leisure activities and thus they can lay a good foundation for classroom learning. Meanwhile, they should record the difficulties and questionable points they may encounter in self-study.

After completing self-study, students can check their learning evaluation, discuss with other students and diverge their thinking. And the teacher can check the completion of assignments in the FiF oral language training system and find some typical problems.

b. While-class Stage

First of all, the teacher lists the problems and difficulties which students may encounter in self-study, such as how to invite others to participate in leisure activities, how to talk about their hobbies, and then organize students to discuss in groups. Through interaction and communication, students can learn from each other and expand their knowledge. During this process, the teacher should explore with students, answer their questions and dispel their doubts, and make sure that every student is taking an active part.

In class, with the help of the teacher, the students participate in such activities as asking and answering questions, making dialogues and role-playing the main content of this unit, communicating with people by telephone. Students complete the construction of knowledge through making dialogues and cooperation. Then the teacher let the students simulate the communication with people by telephone, for example, booking meals by telephone, changing tickets for concerts by telephone, inviting others for entertainment by telephone, meeting friends for dinner by telephone, asking friends to watch movies by telephone and so on. After each group makes presentation, the teacher gives guidance and comments, corrects their pronunciation, answers questions and makes summaries.

Finally, the teacher explains the key words, sentence patterns and habitual expressions in the textbook. Students should complete the relevant listening exercises by watching videos in the textbook, so as to deepen their understanding of common expressions, and achieve the purpose of consolidation.

c. After-class Stage

After class, the teacher assigns the exercises of Expressions and Group Discussions in "Time Out" of the FiF oral language training system according to students' actual level and classroom performance as the extended learning content. Therefore, through self-study before-class, practices while-class and extended consolidation after-class, the students can master the content of the third unit of the textbook Time Out in an all-round way. (Zhou Ye, 2018) 


\section{Ways of Evaluation}

Evaluation runs through every link of the classroom, altogether with students' self-evaluation, students' mutual evaluation and teachers' evaluation. The teacher should give positive and objective evaluation to students' performance, and put forward more professional suggestions for improvement, so as to improve students' oral communicative competence. The teacher should also summarize, analyze and reflect on students' self-study and classroom performance, so as to promote their own teaching and scientific research level.

\section{Achievements of College English Teaching Reform Based on the FiF SMart Learning PlatForm}

In order to verify the influence of the FiF Smart Learning Platform on students' English-speaking ability, we carried out an empirical study among freshmen and sophomores from September 2018 to January 2019. In the process, Class B3, was determined as the experimental class out of all classified freshmen classes of 2018 that are taught according to students' levels, and among the liberal arts departments, the International Economy and Trade Class of 2018, which is from the School of Economics and Management with basically the same entrance examination scores as the experimental class, was selected as the control class. The experimental class is required to use the FiF oral language training system, while the control class doesn't.

There are 43 students in the International Economy and Trade Undergraduate Class from the School of Economics and Management of 2018, with an average score of 46.79 in the entrance examination. Students in this control class are not required to use the FiF oral training platform. Rather, students in the experimental class, B3, having 56 students with an average score of 46.23, are required to complete the oral training task once a week on the FiF oral language training system and their task scores will be included in the final exam results. Teachers assign at least one oral task on the platform every week, including dialogue, paragraph reading, answer questions, role- play topic discussion, presentation and so on. Each mission has basically six or seven days to be finished. After receiving the task, students should arrange their time to practise. The platform will give scores and feedback in time, according to which students can make corresponding improvements and keep training and improving their scores until they get satisfactory results. At the end of each task, the teacher will do spot checks to see if the students have completed the task, and give unified comments on the problems in pronunciation, expression and other aspects. In addition, the teacher will arrange similar topics for students to talk about in the following speaking activities, so as to help students apply the language practiced on the platform to other circumstances in their daily life.

In the classroom, most of the students in the experimental class are willing to speak English, answer questions enthusiastically, and participate in oral activities actively in class. On the contrary, the control class is relatively silent. The students are not active enough to answer questions. In order to verify further the role of FiF oral language training system in improving students' English-speaking ability, our university conducted an oral test for the two classes at the end of the semester. The students in the experimental class did better in the examination than those from the control class. The following table shows the concerning data.

\begin{tabular}{|c|c|c|c|c|c|c|c|}
\hline \multicolumn{2}{|c|}{ Statistics of the Oral Test } \\
\hline $\begin{array}{c}\text { Name of the } \\
\text { Class }\end{array}$ & Headcount & $\begin{array}{c}\text { Average } \\
\text { Score }\end{array}$ & $\begin{array}{c}\text { Number \& } \\
\text { Proportion of } \\
\text { Students over } \\
90 \text { Points }\end{array}$ & $\begin{array}{c}\text { Number \& } \\
\text { Proportion of } \\
\text { Students } \\
\text { Between } \\
80-90 \text { Points }\end{array}$ & $\begin{array}{c}\text { Number \& } \\
\text { Proportion of } \\
\text { Students } \\
\text { Between } \\
70-80 \text { Points }\end{array}$ & $\begin{array}{c}\text { Number \& } \\
\text { Proportion } \\
\text { of Students } \\
\text { Between } \\
60-70 \text { Points }\end{array}$ & $\begin{array}{c}\text { Number \& } \\
\text { Proportion } \\
\text { of Students } \\
\text { Below 60 } \\
\text { Points }\end{array}$ \\
\hline $\begin{array}{c}\text { The } \\
\text { Experimental } \\
\text { Class }\end{array}$ & 56 & 87.32 & $13(23.2 \%)$ & $22(39.3 \%)$ & $15(26.8 \%)$ & $6(10.7 \%)$ & $0(0 \%)$ \\
\hline $\begin{array}{c}\text { The Control } \\
\text { Class }\end{array}$ & 43 & 83.17 & $8(18.6 \%)$ & $15(34.9 \%)$ & $11(25.6 \%$ & $8(18.6 \%)$ & $1(2.3 \%)$ \\
\hline
\end{tabular}

\section{CONCLUSION}

The rapid development of science and technology produces an age of information, intelligence and big data, in which the original teaching models and means have been strongly impacted. New teaching models integrated with technology are emerging constantly, for example, flipped class model, mobile learning, MOOC, micro-class and other models are gradually popular and widely used at home and abroad. Leshan Normal University keeps pace with the times, constantly pushes forward the reform of College English teaching, and takes the opportunity to introduce the FiF Smart Learning Platform of iFLYTEK to enable students to acquire learning resources by various connection channels (WIFI, $4 \mathrm{G}$, etc.) and terminal devices, carrying out self-learning and oral training, thus subverting the learning model of "fixed location with fixed equipment" in the era of digital education. Meanwhile, teachers can check students' learning at any time, get feedback immediately and adjust their teaching strategies and teaching progress accordingly, finally improving the teaching efficiency. With the growing interests in English learning, students' oral English level and comprehensive English ability has been improved significantly. 


\section{REFERENCES}

[1] Gao Dandan, Zhang Jiping. (2008). What technology Brings to Learning: From E-Learning to U-Learning. E-education Research, 7, 14-18.

[2] Guo Shuang. (2011). Exploration of Graded College English Teaching Model under the Network Environment. Modern Education Science, 6, 147-149.

[3] Group Office Working on the Planning Outline of National Medium and Long-term Education Reform and Development. (2010). The Planning Outline of National Medium and Long-term Education Reform and Development. Beijing: China Legal Publishing House.

[4] He Jianwu. (2002). Educational Informatization and Multimedia Instruction Network System. Journal of Xianyang Normal University, 12, Vol.17, No.6, 71-72.

[5] He Kekang. (2004). New Development of Educational Technology Theory from the Perspective of Blending Learning (Part I). E-education Research, 3, 1-6.

[6] Liu Jialiang, Pan Tangxian. (2017). The Policy and Enlightenment of the Development of Educational Informatization in Europe. China Information Technology Education, 12, 81-85.

[7] Liu Ju, Zhang Yunyun. (2015). A Preliminary Study of Adult English Teaching Method Based on Constructivism Theory. The Science Education Article Collects, 16, 171-172.

[8] Liu Zhao. (2011). Study on Dynamic Graded College English Teaching Model. Education and Career, 3B, 109-110.

[9] Lu Haibin. (2009). Exploration of Graded College English Audio-visual Teaching Reform under the Multimedia Teaching Model. Journal of Mudanjiang College of Education, 5, 136-137.

[10] Luan Tao. (2016). The Application of Flipping Classroom Teaching Method in English Teaching in Physical Education Colleges and Universities. Science \& Technology Vision, 5, 33-35.

[11] Ma Ning, Zhou Pengqin, Xie Minyi. (2016). The Present Situation and Enlightenment of Basic Education Informatization in Britain. China Educational Technology, 9, 30-37.

[12] Ma Yuanli, Fei Long. (2009). Taking Advantage of Technology to Promote a New Generation of Learning: New Development of Informatization Strategy of Basic Education in Britain. Distance Education in China, 12, 70-74.

[13] Ma Ning, Zhou Pengqin, Xie Minyi. (2016). The Present Situation and Enlightenment of Basic Education Informatization in Britain. China Educational Technology, 9, 30-37. Abstracted from Department for Education. DfE strategy 2015-2020: $\begin{array}{llll}\text { word-class education are } & \text { and } \\ \text { [DB/OL]. }\end{array}$ https://www.gov.uk/government/publications/dfe-strategy-2015-to-2020-world-class-education-and-care, 2019-04-10.

[14] Ministry of Education of the People's Republic of China. (2012). The Ten-year Development Plan of Education Informatization (2011-2020). Beijing: People's Education Press.

[15] Ministry of Education of the People's Republic of China. (2016). The 13th Five-Year Plan of Education Informatization. Beijing: People's Education Press.

[16] Ministry of Education of the People's Republic of China. (2018). The Action Plan for Education Informatization 2.0. Beijing: People's Education Press.

[17] The State Council of the People's Republic of China. (2017). The 13th Five-Year Plan for the Development of National Education. Beijing: People's Education Press.

[18] Wang Jijun. (2015). Smart Education Promotes Innovation and Transform of Education Paradigm: from the Perspective of Integration of Technology into Education. Modern Educational Technology, 5, 53-58. Abstracted from Smart Australians. Education and innovation in Australia[OL]. Nastem Income and Wealth Report.<http://www.natsem.canberra.edu.au/storage/AMP.NATSEM\%20Income and Wealth Report Smart Australians.pdf.>, 2019-04-10.

[19] Wen Shengfang. (2018). Study on Graded College English Teaching under the Guidance of the Concept of "Result-oriented" Education. English Square, 9, 131-132.

[20] Wu Wanxiang. (2013). Construction of Dynamic Graded College English Teaching Model. Journal of Changchu University of Science and Technology (Social Science Edition), 10, 193-195.

[21] Xie Qiao. (2010). Exploration of the Possibility of Graded College English Teaching. Journal of Language and Literature Studies, 11, 123-125.

[22] Yang Min, Pan Junfeng. (2009). Practice of Graded and Classified College English Audio-visual Teaching Model Based on Computers and Network. Journal of Changchun University of Science and Technology (Higher Education Edition), 1, 117-118.

[23] Zhu Zhiting, Guan yuqi. (2014). The Power of Change in Educational Technology. China Educational Technology, 1, 1-9.

[24] Zhu Cuiping. (2004). On Classroom Teaching Enlightened by Constructionist Theory. Education and Modernization, 2, 76-80.

[25] Zhong Bingliu, Song Shuqiang, Jiao Lizheng. (2013). Research on Teaching Design Based on the Notion of Flipping Classroom Teaching in Informationization Environment. Open Education Research, 2, 58-63.

[26] Zhou Ye. (2018). On Teaching Strategies of Promoting Students'Oral Communicative Competence by Using FiF Oral Training Eco-system, Journal of Leshan Normal University , 6, 111-116.

Xiaoping Tan was born in Leshan, China in 1963. She received her B.A. degree from Sichuan Normal University, China in 1990.

She is currently a professor in the School of Foreign Languages, Leshan Normal University, Leshan, China. Her research interests include linguistics and research on college English teaching. 